\title{
Communication skills development problems among the administrators in the sport activity at the private sport clubs
}

\section{*Dr/ Younis Anwar Younis Eisawy}

\section{Abstract:}

The special sports clubs are considered as ones of the most advanced sports clubs which are interesting in providing the sportive services for those who are frequently go there.

In spite of the selection of distinguished administrators for the sports activity according to their different cultural and social levels, this needs to be always polished so as to appear according to the suitable practice for those clubs. The study has aimed at knowing the most import problems of the communication skills development encountered by the administrators .

The researchers has used the experimental method by using the one single group according to the pre and post measurement level, so as it is suitable for the study nature.

The study sample has included (78) administrators from the sports activities in the special sports clubs ( Pegasus Dream Land clubs- Paverly Hills - Palm Hills, El Rabwa, Wadi Digla)

The most important results of this study is the existence of some financial problems represented in the high cost paid for the training of the administrators and because of not having a priority, and personal problems, which were represented in the factor of the personal ability and the skill, and that some of the administrators consider this as an additional effort in addition to their few work hours, they don't continue in the work for the training and a personal problems which being represented in style of the program of developing the communication skills which aren't suitable for the administrators, as they are boring and needed to be updated, in addition to the disqualification of its providers; as some of the Clubs managers are lacking the awareness to the importance and the role of communication skills for administrators.

\section{Introduction:}

Lecturer dept. .of sports management, Faculty of physical education ,beni suef University

Assiut Journal For Sport Science Arts 
The special sports clubs are considered as ones of the most advanced sports clubs which are interesting in providing the sportive services for those who are frequently go there; as those who visit these clubs are always looking forward to a distinguished and distinctive level of services, which makes the method of introducing the services, their kinds and their development as one of the priorities of higher administration of those clubs, particularly that this shall be the competitive point among those clubs and an attractive factor for memberships and the increasing demand for those services.

Ahmed Sayed Abd El Fattah 2012 said that the sports clubs are by nature considered as organizations which are providing a high demand service product according to the economic concept. Thus, the service product is characterized by the high level of communication with the customer and the beneficiary, namely: the direct communication between the service provider and customer. (20-1).
Zaki Mohamed Hasan 2010 indicates that the communication is the expression of relationships among the individuals; this is intended to convey an idea or a fixed meaning in the mind of someone to the mind of another one or to the minds of a group of persons. The interaction among individuals takes place by the communication process. (7-14:20).

Hani El Damour refers also (2002 ad) that communication level can be defined by means of classifying the services according to the degree of the thickness of the Force Power usage (the services which rely upon the Human Element) that is to be opposite to the services that depend on the tools and the equipment ( The services which rely upon the tools and the equipment); as some of the organization personnel have a direct communication with the customers and the others don't have any kind of communication with the customers. (10-11:27)

Both Kamal El Din Abd El Rahman Darwish and Mohamed Mohammed El Hamahmi (1997), each of them sees that the communication is 
considered as an old and known process since the dawn of time. However, this process had had various forms and used a lot of modern tools and methods in order to keep pace with the scientific and technical progress that has widely spread in the modern societies. (9-175)

Mohamed El Serafi (2006) defines it as a process of producing, transporting and understanding the information, ideas, opinions and the feelings from a person to another ( or from a group to another) with aim of affecting in him or in her and causing the required response. (4-16:15)

David C. Watt (2003) describes the communication that it is the issuance, receipt or exchange of the information, to the degree that the sent content shall be clearly understood by all concerned persons and managers of the organization. (13-101)

Hasan Ahmed El Sahfee (2005) clarifies, in this respect, that the effective communication is the process of publishing and evaluating correct information, clear facts, valid news, accurate subjects, definite incidents, and logical ideas for the service of the public interest. (2-12) .

\section{The Research Problem:}

Within the work of the researcher into the field of the private clubs, which have a distinguished staff and service providers, the communication skills of many of them and their abilities to communicate with the members at all their various cultural and social levels are always needed to be developed for the proper appearance of these clubs. Thus, the current search is addressing the communication skills development problems faced by those who are working in the sport clubs.

\section{The Research Objectives:}

- Identifying the most important communication skills development problems faced by those who are working in the special sport clubs.

- Identifying the interest of administration in special sport clubs to develop the communication skills of the administrators in the sportive activity.

\section{The Research Hypotheses:}

- There are planning problems faced by the special sports clubs administration which impeded the development of the administrator's skills in the sports activity.

- $\quad$ There are some financial problems faced by the clubs administration, which impeded the development of the administrator's skills in the sports activity 
- There are some problems in the sportive activity faced by the sports clubs administration which prevent the development and enhancement of its skills.

The Research method:

The researcher has adopted the descriptive method because of its suitability for the nature of this study.

The research Community: The research community includes those who are the working in the special sports clubs at Giza Governorate.
The research Sample:

The research sample has been intentionally selected among those who are working in the sportive activity administration in special sports clubs of Giza.

Data collection tools: The questionnaire.

Data Collection Form: The researcher has designed the questionnaire form.

The sample description is indicated in the following table:

Table No. (1)

\begin{tabular}{c|c|c|c}
\hline \hline $\begin{array}{c}\text { Serial } \\
\text { No. }\end{array}$ & Name of the club & Club type & $\begin{array}{c}\text { The sample } \\
\text { number }\end{array}$ \\
\hline \hline 1 & Pegasus Dream Land & A private one & 16 \\
\hline 2 & El Rabua & A private one & 10 \\
\hline 3 & Palmi Hills & A private one & 11 \\
\hline 4 & Black Pool & A private one & 12 \\
\hline 5 & Beverli Hills & A private one & 14 \\
\hline 6 & Wadi Digla & A private one & 15 \\
\hline \hline
\end{tabular}

The statistic treatments used:

Presentation of results:

Table (2)

The responses of the research sample which took place into the questionnaire about the problem of the communication skills development among the administrators - the first axe entitled " the administrative problems" $N=78$

\begin{tabular}{c|c|c|c|c}
\hline \multicolumn{2}{c|}{ Yes } & \multicolumn{2}{c}{ to a certain extent } \\
\hline \hline The term & $\mathbf{K}$ & \% & $\mathbf{K}$ & \% \\
\hline \hline 1 & 55 & 70.51 & 14 & 17.95 \\
\hline 2 & 47 & 60.26 & 27 & 34.62 \\
\hline 3 & 50 & 64.10 & 16 & 20.51 \\
\hline 4 & 50 & 64.10 & 22 & 28.21 \\
\hline \hline
\end{tabular}

Assiut Journal For Sport Science Arts 
Follow Table (2)

The responses of the research sample which took place into the questionnaire about the problem of the communication skills development among the administrators - the first axe entitled " the administrative problems" $N=78$

\begin{tabular}{|c|c|c|c|c|c|}
\hline \multicolumn{4}{|c|}{ Yes } & \multicolumn{2}{|c|}{ to a certain extent } \\
\hline \multicolumn{2}{|c|}{ The term } & $\overline{\mathbf{K}}$ & $\%$ & $\mathbf{K}$ & $\%$ \\
\hline \multicolumn{2}{|c|}{ 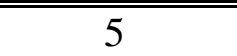 } & 44 & $\overline{56.41}$ & 24 & 30.77 \\
\hline \multicolumn{2}{|c|}{6} & 54 & 69.23 & 18 & 23.08 \\
\hline \multicolumn{2}{|c|}{7} & 44 & 56.41 & 29 & 37.18 \\
\hline \multicolumn{2}{|c|}{8} & 54 & 69.23 & 19 & 24.36 \\
\hline \multicolumn{2}{|c|}{9} & 49 & 62.82 & 22 & 28.21 \\
\hline \multicolumn{2}{|c|}{10} & 57 & 73.08 & 18 & 23.08 \\
\hline \multicolumn{2}{|c|}{11} & 51 & 65.38 & 20 & 25.64 \\
\hline \multicolumn{2}{|c|}{12} & 52 & 66.67 & 20 & 25.64 \\
\hline $\mathbf{K}$ & $\%$ & $\overline{\mathrm{K} 2}$ & $\begin{array}{c}\begin{array}{c}\text { Estimated } \\
\text { total }\end{array} \\
\end{array}$ & $\begin{array}{c}\text { Relative } \\
\text { weight }\end{array}$ & Order \\
\hline 9 & 11.54 & 49.000 & 202 & $86.32 \%$ & 4 \\
\hline 4 & 5.13 & 35.615 & 199 & $85.04 \%$ & 8 \\
\hline 12 & 15.38 & 33.538 & 194 & $82.91 \%$ & 11 \\
\hline 6 & 7.69 & 38.154 & 200 & $85.47 \%$ & 6 \\
\hline 10 & 12.82 & 22.462 & 190 & $81.20 \%$ & 12 \\
\hline 6 & 7.99 & 48.000 & 204 & $87.18 \%$ & 3 \\
\hline 5 & 6.41 & 22.769 & 195 & $83.33 \%$ & 10 \\
\hline 5 & 6.41 & 49.000 & 205 & 87.61 & 2 \\
\hline 7 & 8.97 & 34.846 & 198 & $84.62 \%$ & 9 \\
\hline 3 & 3.85 & 59.769 & 210 & 89.74 & 1 \\
\hline 7 & 8.97 & 39.308 & 200 & 85.47 & 6 \\
\hline 6 & 7.69 & 42.769 & 202 & $86.32 \%$ & 4 \\
\hline & & Total & 2399 & 85.43 & \\
\hline
\end{tabular}

The K2 tabulated value at the level of 0.05 is 5.991

The table No. 2 refers to the repetitions, the percentages of the research sample responses, the value of $\mathrm{K} 2$ and the estimated total, the relative weight and the order of the first axe terms entitled "The administrative problems" to illustrate the problems of communication skills development among the administrators. 
Table (3)

Description of the sample responses appeared into the questionnaire of the communication skills development problems among the administrators "Financial Problems" N=78

\begin{tabular}{|c|c|c|c|c|c|}
\hline The term & $\bar{K}$ & \multicolumn{2}{|c|}{$\%$} & $\bar{K}$ & $\%$ \\
\hline 1 & 36 & \multicolumn{2}{|c|}{46.15} & 27 & 34.62 \\
\hline 2 & 39 & \multicolumn{2}{|c|}{50.00} & 29 & 37.18 \\
\hline 3 & 46 & \multicolumn{2}{|c|}{58.97} & 26 & 33.33 \\
\hline 4 & 42 & \multicolumn{2}{|c|}{53.85} & 27 & 34.62 \\
\hline 5 & 39 & \multicolumn{2}{|c|}{50.00} & 28 & 35.90 \\
\hline 6 & 39 & \multicolumn{2}{|c|}{50.00} & 29 & 37.18 \\
\hline 7 & 49 & \multicolumn{2}{|c|}{62.82} & 23 & 29.49 \\
\hline 8 & 52 & \multicolumn{2}{|c|}{66.67} & 23 & 29.49 \\
\hline 9 & 35 & \multicolumn{2}{|c|}{44.87} & 29 & 37.18 \\
\hline 10 & 38 & \multicolumn{2}{|c|}{48.72} & 28 & 35.90 \\
\hline 11 & 52 & \multicolumn{2}{|c|}{66.67} & 22 & 28.21 \\
\hline$\overline{\mathbf{K}}$ & $\%$ & $\overline{\overline{K 2}}$ & $\begin{array}{c}\text { Estimated } \\
\text { total }\end{array}$ & $\begin{array}{c}\text { Relative } \\
\text { weight }\end{array}$ & $\overline{\text { Order }}$ \\
\hline 15 & 19.23 & 8.538 & 177 & $75.64 \%$ & 10 \\
\hline 10 & 12.82 & 16.692 & 185 & $79.6 \%$ & 6 \\
\hline 6 & 7.69 & 30.769 & 196 & 83.79 & 4 \\
\hline 9 & 11.54 & 21.000 & 189 & $80.77 \%$ & 5 \\
\hline 11 & 14.10 & 15.308 & 184 & $78.63 \%$ & 8 \\
\hline 10 & 12.82 & 16.692 & 185 & 79.06 & 6 \\
\hline 6 & 7.69 & 36.077 & 199 & $85.04 \%$ & 3 \\
\hline 3 & 3.85 & 46.692 & 205 & $87.61 \%$ & 1 \\
\hline 14 & 17.95 & 9.000 & 177 & $75.64 \%$ & 10 \\
\hline 12 & 15.38 & 13.231 & 182 & $77.78 \%$ & 9 \\
\hline 4 & 5.13 & 45.231 & 204 & $87.18 \%$ & 2 \\
\hline & & Total & 2083 & $80.92 \%$ & \\
\hline
\end{tabular}

The K2 tabulated value at the level of 0.05 is 5.991

The table No. (3) refers to the repetitions and the percentages of the research sample responses, the value of $\mathrm{K} 2$, the estimated total, the relative weight, and the order for all terms of the second axe entitled "The financial problems" to illustrate the problems communication skills 
development among the administrators .

Table (4)

Description of the sample responses appeared into the questionnaire of the communication skills development problems among the administrators, third axe entitled "Personal Problems" N=78

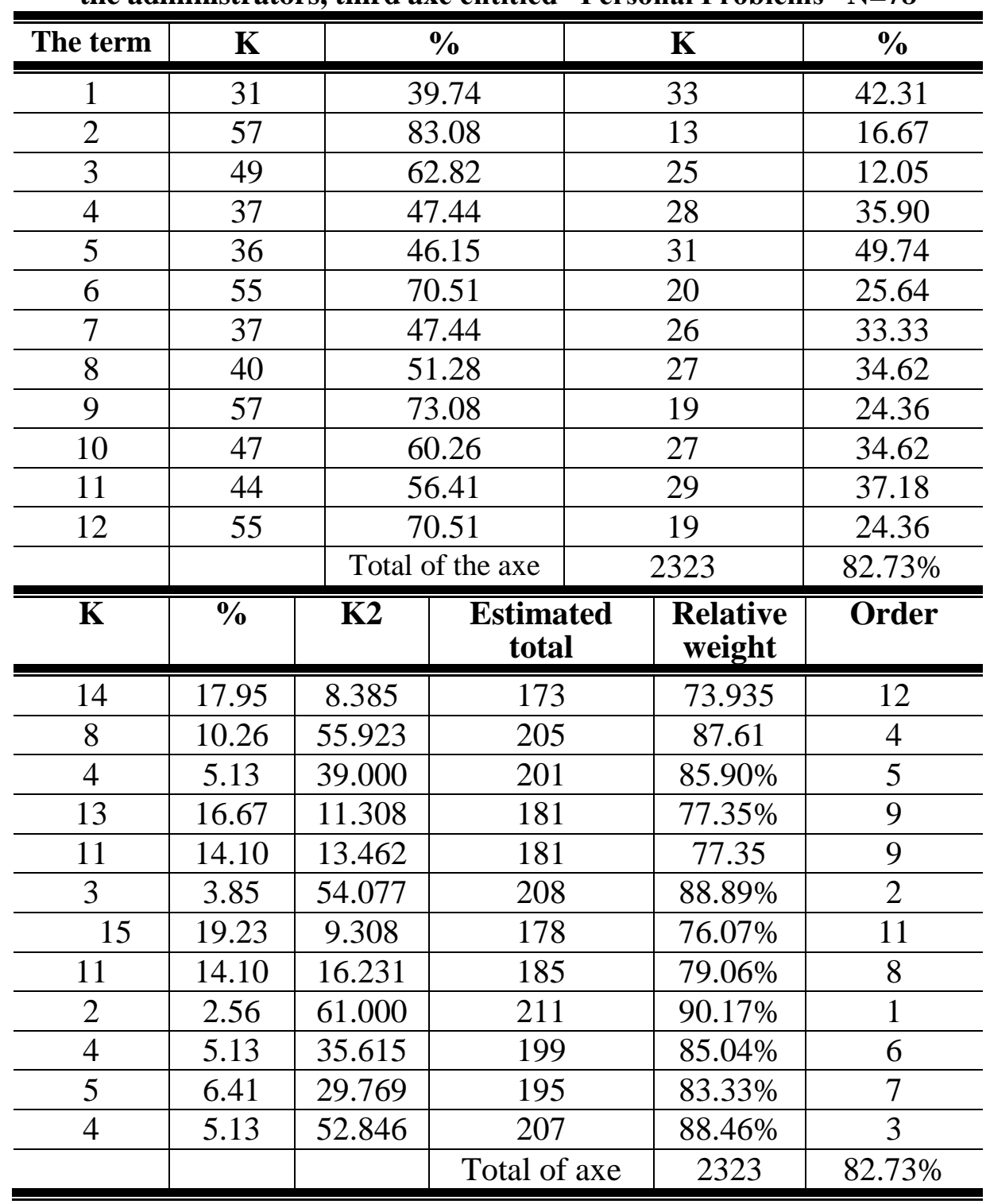

The K2 tabulated value at the level of 0.05 is 5.991 
The table (4) refers to the repetitions and the percentage of the research sample responses, the value of $\mathrm{K} 2$, the estimated total, the relative weight and the order of

Table (5)

Description of the sample responses appeared into the questionnaire of the communication skills development problems among the administrators "Subjective Problems" N=78

\begin{tabular}{|c|c|c|c|c|c|}
\hline The term & $\bar{K}$ & \multicolumn{2}{|l|}{$\%$} & $\bar{K}$ & $\%$ \\
\hline 1 & 45 & \multicolumn{2}{|c|}{57.69} & 29 & 37.18 \\
\hline 2 & 52 & \multicolumn{2}{|c|}{66.67} & 21 & 26.92 \\
\hline 3 & 49 & \multicolumn{2}{|c|}{62.82} & 23 & 29.49 \\
\hline 4 & 51 & \multicolumn{2}{|c|}{65.38} & 23 & 29.49 \\
\hline 5 & 55 & \multicolumn{2}{|c|}{70.51} & 17 & 21.79 \\
\hline 6 & 50 & \multicolumn{2}{|c|}{64.10} & 24 & 30.77 \\
\hline 7 & 36 & \multicolumn{2}{|c|}{46.15} & 30 & 38.46 \\
\hline 8 & 38 & \multicolumn{2}{|c|}{48.72} & 30 & 38.46 \\
\hline 9 & 57 & \multicolumn{2}{|c|}{73.08} & 19 & 24.36 \\
\hline 10 & 47 & \multicolumn{2}{|c|}{60.26} & 27 & 34.62 \\
\hline 11 & 44 & \multicolumn{2}{|c|}{56.41} & 29 & 37.18 \\
\hline 12 & 55 & \multicolumn{2}{|c|}{70.51} & 19 & 24.36 \\
\hline$\overline{\mathbf{K}}$ & $\%$ & $\overline{\mathrm{K} 2}$ & $\begin{array}{c}\text { Estimated } \\
\text { total }\end{array}$ & $\begin{array}{c}\text { Relative } \\
\text { weight }\end{array}$ & Order \\
\hline 4 & 5.13 & 32.846 & 197 & $84.19 \%$ & 6 \\
\hline 5 & 6.41 & 43.923 & 2.3 & $86.75 \%$ & 2 \\
\hline 6 & 7.69 & 36.077 & 199 & $85.04 \%$ & 5 \\
\hline 4 & 5.13 & 40.923 & 202 & $86.32 \%$ & 2 \\
\hline 6 & 7.69 & 50.846 & 205 & $87.61 \%$ & 1 \\
\hline 4 & 5.13 & 40.923 & 202 & $86.32 \%$ & 4 \\
\hline 12 & 15.38 & 12.000 & 180 & $76.92 \%$ & 8 \\
\hline \multirow[t]{2}{*}{10} & 12.82 & 16.000 & 184 & $78.63 \%$ & 7 \\
\hline & & & $\begin{array}{l}\text { Total of } \\
\text { the axe }\end{array}$ & 1573 & $84.03 \%$ \\
\hline
\end{tabular}

The K2 tabulated value at the level of 0.05 is 5.991

Assiut Journal For Sport Science Arts terms of third axe entitled "the personal problems" to illustrate the communication skills development problems among the administrators. 
The table (5) refers to the repetitions and the percentage of the research sample responses, the value of $\mathrm{K} 2$, the estimated total, the relative weight and the order of terms of fourth axe entitled "the subjective problems" to illustrate the communication skills development problems among the administrators in the sports activity at the special sports clubs.

\section{Table No.(6)}

Description of the sample responses appeared into the questionnaire of the communication skills development problems among the administrators in the sports activity in the special sports clubs, fifth axe entitled "Planned Problems" . N= 78

\begin{tabular}{|c|c|c|c|c|c|}
\hline The term & $\overline{\mathbf{K}}$ & \multicolumn{2}{|l|}{$\%$} & $\bar{K}$ & $\%$ \\
\hline 1 & 71.79 & \multicolumn{2}{|l|}{20} & 25.64 & 2 \\
\hline 2 & 35 & \multicolumn{2}{|l|}{44.87} & 31 & 39.74 \\
\hline 3 & 46 & \multicolumn{2}{|l|}{58.97} & 19 & 24.36 \\
\hline 4 & 39 & \multicolumn{2}{|l|}{50.00} & 25 & 32.05 \\
\hline 5 & 46 & \multicolumn{2}{|l|}{58.97} & 24 & 30.77 \\
\hline 6 & 44 & \multicolumn{2}{|l|}{56.41} & 27 & 34.62 \\
\hline 7 & 53 & \multicolumn{2}{|l|}{07.95} & 19 & 24.36 \\
\hline 8 & 40 & \multicolumn{2}{|l|}{51.28} & 27 & 34.62 \\
\hline 9 & 33 & \multicolumn{2}{|c|}{42.31} & 32 & 41.03 \\
\hline 10 & 40 & \multicolumn{2}{|l|}{51.28} & 28 & 35.90 \\
\hline$\overline{\mathbf{K}}$ & $\%$ & $\overline{\mathrm{K} 2}$ & $\begin{array}{c}\begin{array}{c}\text { Estimated } \\
\text { total }\end{array} \\
\end{array}$ & $\begin{array}{c}\text { Relative } \\
\text { weight }\end{array}$ & Order \\
\hline 7 & 8.97 & 26.385 & 193 & $82.48 \%$ & 4 \\
\hline 6 & 7.69 & 45.308 & 203 & $86.75 \%$ & 7 \\
\hline 11 & 14.10 & 16.231 & 185 & $79.06 \%$ & 7 \\
\hline 13 & 16.67 & 9.769 & 176 & $75.21 \%$ & 10 \\
\hline 10 & 12.82 & 17.538 & 186 & $79.49 \%$ & 6 \\
\hline & & & $\begin{array}{c}\text { Total of the } \\
\text { axe }\end{array}$ & 1896 & $81.03 \%$ \\
\hline
\end{tabular}

The K2 tabulated value at the level of 0.05 is 5.991

Table (6) refers to the repetitions and the percentage of the research sample responses, the value of $\mathrm{K} 2$, the 
estimated total, the relative weight and the order of terms of fifth axe entitled "the planned problems" to illustrate the communication skills

\section{Table (7)}

Description of the sample responses on the axes and the total of problems questionnaire of communication skills development among administrators in the special sports clubs. $N=78$

\begin{tabular}{c|c|c|c|c}
\hline \hline s.No. & Axe & $\begin{array}{c}\text { Estimated } \\
\text { total }\end{array}$ & $\begin{array}{c}\text { Relative } \\
\text { weight }\end{array}$ & Order \\
\hline \hline 1 & $\begin{array}{c}\text { The administrative } \\
\text { problems }\end{array}$ & 2399 & $85.43 \%$ & \\
\hline 2 & The financial problems & 2083 & $80.92 \%$ & \\
\hline 3 & The personal problems & 2323 & $82.73 \%$ & \\
\hline 4 & The subjective problems & 1573 & $84.03 \%$ & \\
\hline 5 & The planned problems & 1896 & $81.03 \%$ & \\
\hline & $\begin{array}{c}\text { Total of the } \\
\text { questionnaire }\end{array}$ & 10247 & $82.84 \%$ & \\
\hline \hline
\end{tabular}

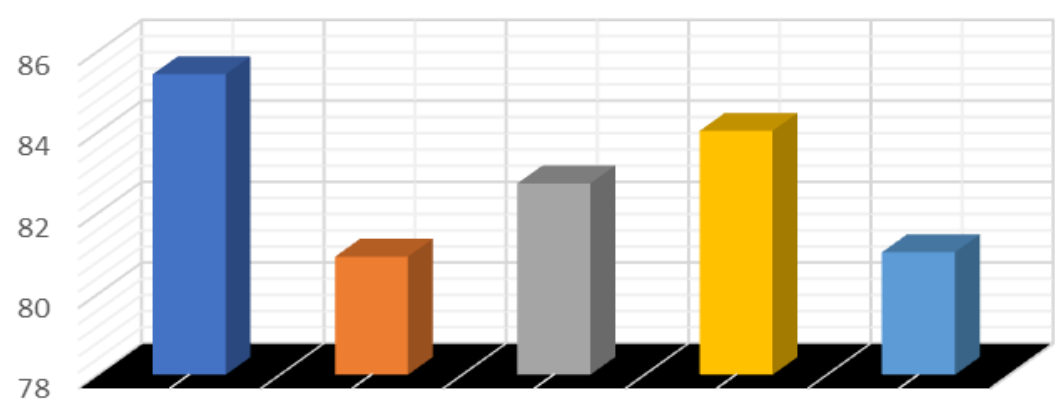

Figure (1)

The relative weight for questionnaire axes of the communication skills development problems among administrators in the sports activity, at the special sports clubs

Table (7) and figure (1) indicate the estimated total and the percentage weight, and the arrangement questionnaire for the communication of the skills 
development problems among the administrators in the sports activity at the special sports clubs; as the axe of 'administrative problems' was ranked the first one with a relative weight of $(85.43 \%)$, followed by the axe of "Subjective problems" which ranked second one with relative weight of $(84.03 \%)$, then the axe of " Personal problems" ranked as the third one with a relative weight of $(82.73 \%)$, then the axe of "planned problems" ranked as the fourth one with a relative weight of $(81.03 \%)$, and finally, the axe of "the financial problems" ranked as the fifth one with a relative weight of $(80.92 \%)$.

\section{Results Discussion:}

Table (2) refers to the repetitions and the percentage of the research sample responses, the value of $\mathrm{K} 2$, the estimated total, the relative weight and the order of all terms of first axe entitled "the administrative problems" to illustrate the communication skills development problems among the administrators in the sports activity at the special sports clubs. The table indicates also that the terms of the first axe entitled " the administrative problems" illustrating the communication skills development problems among the administrators having the highest relative weight are as follows:

- $\quad$ The term No (10) which has stipulated: "The administrative duties and commitments of the administrators along with their abilities to attend the training courses to improve their performance" was ranked as the first one with relative weight of $(89.74 \%)$, while the $\mathrm{K} 2$ value was statistically significant at the level of $(0.05)$ and towards the response "Yes".

- $\quad$ The term No (6) which has stipulated: "The administration is seeking a non-conflict between the communication skills courses times and the business requirements" was ranked as the third one with relative weight of $(87.18 \%)$, while the K2 value was statistically significant at the level of $(0.05)$ and towards the response "Yes".

The table indicates also that the terms of the first axe entitled " the administrative 
problems" illustrating the communication skills development problems among the administrators in sports activity at the special sports clubs having the lowest relative weight are as follows:

- $\quad$ The term No (5) which has stipulated that "the administration is seeking to measure the extent to which the administrators benefit from the training courses through practical duties and tests" was ranked as the twelfth one with relative weight of $(81.20 \%)$, while the $\mathrm{K} 2$ value was statistically significant at the level of (0.05) and towards the response "Yes".

Table (3) refers to the repetitions and the percentages of the research sample responses, the value of $\mathrm{K} 2$, the estimated total, the relative weight and the order of all terms of second axe entitled "the financial problems" to illustrate the communication skills development problems among the administrators in the sports activity at the special sports clubs. The table indicates also that the terms of the second axe entitled " the financial problems" illustrating the communication skills development problems among the administrators having the highest relative weight are as follows:

- $\quad$ The term No (8) which has stipulated: "There is an increase in the cost of basic appearance and incentive services which comes as a priority before the personnel training programs" was ranked as the first one with relative weight of $(87.61 \%)$, while the $\mathrm{K} 2$ value was statistically significant at the level of (0.05) and towards the response "Yes".

The table indicates also that the terms of the second axe entitled " the financial problems" illustrating the communication skills development problems among the administrators in sports activity at the special sports clubs having the lowest relative weight are as follows:

- The term No (1) which has stipulated: "The club has the appropriate facilities to provide the administrators with the courses and programs of communication skills development" and the term No. (9) which has stipulated:

"The 
administration shall bear transportation fees allocated to attend training courses outside the clubs" were ranked as the tenth one with relative weight of $(75.64 \%)$, while the $\mathrm{K} 2$ value was statistically significant at the level of (0.05) and towards the response "Yes".

This is consistent with the second hypothesis stipulated: "There are financial problems in the administration of the special sports clubs to develop the administrators' skills in the sport activity".

Table (4) refers to the repetitions and the percentage of the research sample responses, the value of $\mathrm{K} 2$, the estimated total, the relative weight and the order of all terms of third axe entitled "the personal problems" to illustrate the communication skills development problems among the administrators in the sports activity at the special sports clubs.

The table indicates also that the terms of the third axe entitled " the personal problems" illustrating the communication skills development problems among the administrators having the highest relative weight are as follows:

- $\quad$ The term No (9) which has stipulated: "Some administrators have a job different from their study field and they are obliged to perform it temporarily, which makes this job, for them, exceptional work having no need to be reinforced" was ranked as the first one with relative weight of $(91.17 \%)$, while the K2 value was statistically significant at the level of (0.05) and towards the response "Yes".

The table indicates also that the terms of the third axe entitled " the personal problems" illustrating the communication skills development problems among the administrators having the lowest relative weight are as follows:

- The term No (4) which
has stipulated: "Some administrators only work a few number of hours, which make them don't benefit from training programs and courses" was ranked as the tenth one with relative weight of $(76.92 \%)$, while the K2 value was statistically 
significant at the level of (0.05) and towards the response "Yes".

Table (5) refers to the repetitions and the percentage of the research sample responses, the value of $\mathrm{K} 2$, the estimated total, the relative weight and the order of all terms of fourth axe entitled "the subjective problems" to illustrate the communication skills development problems among the administrators in the sports activity at the special sports clubs.

The table indicates also that the terms of the fourth axe entitled "the subjective problems" illustrating the communication skills development problems among the administrators having the highest relative weight are as follows:

- The term No (5) which has stipulated: "Communication skills development and reinforcement programs methods are inconsistent with the administrators in the special clubs" was ranked as the first one with relative weight of $(87.61 \%)$, while the K2 value was statistically significant at the level of $(0.05)$ and towards the response "Yes".

The table indicates also that the terms of the fourth axe entitled " the subjective problems" illustrating the communication skills development problems among the administrators having the lowest relative weight are as follows:

- The term No (1) which has stipulated: "Communication skills development and reinforcement programs for the administrators in the special clubs are decreased" was ranked as the sixth one with relative weight of (84.19\%), while the K2 value was statistically significant at the level of (0.05) and towards the response "Yes".

- The term No (7) which has stipulated: "It is difficult to use the communication skills development and reinforcement programs inside the club due to the service nature of this place" was ranked as the eighth one with relative weight of (76.92\%), while the K2 value was statistically significant at the level of (0.05) and towards the response "Yes". 
This is consistent with the third hypothesis stipulated: "There are subjective problems in the administration of the special sports clubs to develop and reinforce the administrators' skills in the sport activity".

Table (6) refers to the repetitions and the percentage of the research sample responses, the value of $\mathrm{K} 2$, the estimated total, the relative weight and the order of all terms of fifth axe entitled "the planned problems" to illustrate the communication skills development problems among the administrators in the sports activity at the special sports clubs.

The table indicates also that the terms of the fifth axe entitled "the planned problems" illustrating the communication skills development problems among the administrators in sports activity at the special sports clubs having the highest relative weight are as follows:

- The term No (1) which has stipulated: "There are administration's clear objectives to develop and reinforce the communication skills of administrators in special clubs" was ranked as the first one with relative weight of $(89.74 \%)$, while the K2 value was statistically significant at the level of $(0.05)$ and towards the response "Yes".

The table indicates also that the terms of the fifth axe entitled "the planned problems" illustrating the communication skills development problems among the administrators in sports activity at the special sports clubs having the lowest relative weight are as follows:

- The term No (4) which has stipulated:

"The

administration distributes the communication skills development programs on the administrators according to appropriate timetables" was ranked as the eighth one with relative weight of (77.35\%), while the K2 value was statistically significant at the level of (0.05) and towards the response "Yes".

\section{Conclusions:}

The most important results of this study that there are financial problems represented by the high cost of training the administrators and being unimportant, in addition 
to the personal problems represented by the factor of the personal ability and the skill, which seen by some administrators as an addition effort, together with their few hours of work. Moreover, there are subjective problems represented by the conflict between the communication skills development programs methods and the administrators; as these methods are modest and need to be updated, and lead to boredom, in addition to the inefficiency of those who are interesting in it. Furthermore, there are administrative problems represented by the lack of awareness concerning the importance and the role of the communication skills for the administrators.

\section{The Recommendations:}

This research gives the following Recommendations:

- The necessity to raise the awareness of the importance of the communication skills training courses for the personnel, whether for the administration or the staff themselves.

- The necessity to prepare regular timetables for developing and reinforcing the communication

skills, particularly those who are dealing directly with the public.

- The necessity to update the communication skills development and reinforcement programs with its information provided to be suitable for what can be obtained from the information networks and the internet.

\section{The Arab References:}

\section{1- Ahmed Sayed Ahmed Abd}

El Fattah: "The organizing citizenship and the content of the work and their relationships with the good quality of the personnel into the sports clubs, this is a Master's Degree Research, which isn't published one, Faculty of Sports Education for the Males, Helwan University, Cairo, 2012 .

\section{2- Hasan Ahmed El Sahfee :}

The communication in the sports physical education, T1 the orbit of the faithfulness, Alexandria, 2005.

\section{3- Mohamed Ahmed Abbas :}

An analytical study for the investment into the private sports clubs in The Arab Republic of Egypt - Master's degree research which isn't a published one Faculty of 
Sports Education for the males

- Helwan University - 2008

4- Mohamed El Serafi : The serial of the administrative training, The International Horas foundation for publication and printing, Alexandria, 1996

\section{5- Mohamed Abd El Ghani}

Hasan Helal : The skills of the communication for the art of listening and the modernized one, T3, The center of the development to the practice and the development.

6- Rehab Ali Amin Osman: The requirements of the effective communication management in the good and whole out for the realization of the goals of the Egyptian Union for the swimming, A Doctor's Degree, Faculty of the sports education, for girls, Alexandria University,(2008).

7- Zaki Mohamed Mohamed Hasan: The communication in the sports field, Dar El Ketab El Hadith (Modern book home) The first edition, Cairo, 2010

8- Abd Allah Amin : the group of the changeableness affecting the understanding of the consumers for the fine quality of the sanitary service and its marketing effects " A field study including the application on the private hospitals in Cairo, The first number (first edition)- El Zagazig university- Banha Branch , Cairo 1998

9- Kamal El Din Abd El Rahman Darwish, Mohamed Mohammed El Hamahmi: A modern vision for the recreation and the free times, The center of the Book for Publication, Cairo, 1977

10- Hani Hamed El Damour: Marketing of the services, Wael Home for publication, the first edition 2002

\section{The Foreign References:}

11- Athanasios, Laios: Department of Physical education \& Sports Science, Democritus University of Thrace Kmotini, Greece, PUBLISHER' United Kingdom, Emerald Group Publishing limited 2005

12- Bloom G. Schiinke R, Salamela J. development of communication skills by elite basketball coaches" coaching and sport science journal rome, 1997

13- David C.Watt management and administration Sports, published in the Taylor \& Francis e-Library, 2003 